\title{
Pooled prevalence of deep vein thrombosis among coronavirus disease 2019 patients
}

Ying Wang ${ }^{1 \dagger}$, Li Shi ${ }^{1 \dagger}$, Haiyan Yang ${ }^{1^{*}}$ D, Guangcai Duan ${ }^{1}$ and Yadong Wang ${ }^{2^{*}}$

Keywords: Coronavirus disease 2019, Deep vein thrombosis, Prevalence

To the editor,

The article by Ren et al. reported that there was an extremely high incidence (85.4\%) of lower extremity deep venous thrombosis (DVT) among 48 patients with severe coronavirus disease 2019 (COVID-19) in Wuhan, China [1]. As the global pandemic of COVID-19, there have been several studies on the incidence, risk factors, and preventive strategies of DVT [1-4]. However, the incidence of DVT has been reported diversely among different clinical centers. Thus, we performed a meta-analysis to estimate the pooled prevalence of DVT in confirmed COVID-19 patients.

We searched PubMed, EMBASE, Web of Science, and medRxiv databases until June 22, 2020, for relevant studies, using the keywords ("coronavirus" or "COVID-19" or "SARS-CoV-2" or "2019-nCoV") and ("thrombosis" or "thrombi" or "thrombus"). In addition, we screened out the relevant potential articles in the references of selected studies. Articles reporting the prevalence of DVT in confirmed COVID-19 patients were included.

The pooled prevalence and its 95\% confidence interval $(\mathrm{CI})$ were used to estimate the combined effects. We calculated the prevalence estimates with the variance stabilizing double arcsine transformation $[5,6]$. The heterogeneity among studies was assessed with the $I^{2}$ statistic and Cochran's $Q$ test.
The meta-regression and subgroup analysis were used to investigate the potential heterogeneity sources (such as sample size, prevalence of prophylaxis in COVID-19 patients, location, design of studies, screening methods of DVT, and COVID-19 patients in intensive care unit (ICU)). We chose Egger's test and Begg's test to assess publication bias. All analyses were performed using the Stata 11.2 (StataCorp, College Station, TX), and a twotailed $P$ value $<0.05$ was considered to be statistically significant.

A total of 1202 records were initially identified by our searches. We finally included 28 articles in our meta-analysis. The basic characteristics of included studies are shown in Table 1. There were 397 DVT cases in a total of 4138 COVID-19 patients. The pooled estimate of the prevalence for DVT was $16 \%$ by using a random-effects model (95\% CI $10-23 \%$, $P<0.01, I^{2}=96.81, Q=846.41, P<0.01$ ) (Fig. 1a). According to patients' geographic location, the much higher pooled prevalence of DVT was found in COVID-19 patients from China $(30 \%, 95 \%$ CI $2-$ $\left.72 \%, P=0.02, I^{2}=98.73 \%, Q=313.90, P<0.01\right)$ compared with those from western countries $(13 \%, 95 \%$ CI $8-19 \%, P<0.01, I^{2}=95.62 \%, Q=502.07, P<0.01$ ) (Fig. 1b). Twenty articles clearly reported the prevalence of DVT in COVID-19 patients treated in ICU or non-ICU. The pooled prevalence of DVT in

* Correspondence: yhy@zzu.edu.cn; wangyd76@163.com

'Ying Wang and Li Shi contributed equally to this work.

${ }^{1}$ Department of Epidemiology, College of Public Health, Zhengzhou

University, No. 100 of Science Avenue, Zhengzhou 450001, China

${ }^{2}$ Department of Toxicology, Henan Center for Disease Control and

Prevention, No. 105 of South Nongye Road, Zhengzhou 450016, China

C C The Author(s). 2020 Open Access This article is licensed under a Creative Commons Attribution 4.0 International License, which permits use, sharing, adaptation, distribution and reproduction in any medium or format, as long as you give appropriate credit to the original author(s) and the source, provide a link to the Creative Commons licence, and indicate if changes were made. The images or other third party material in this article are included in the article's Creative Commons licence, unless indicated otherwise in a credit line to the material. If material is not included in the article's Creative Commons licence and your intended use is not permitted by statutory regulation or exceeds the permitted use, you will need to obtain permission directly from the copyright holder. To view a copy of this licence, visit http://creativecommons.org/licenses/by/4.0/. The Creative Commons Public Domain Dedication waiver (http://creativecommons.org/publicdomain/zero/1.0/) applies to the data made available in this article, unless otherwise stated in a credit line to the data. 


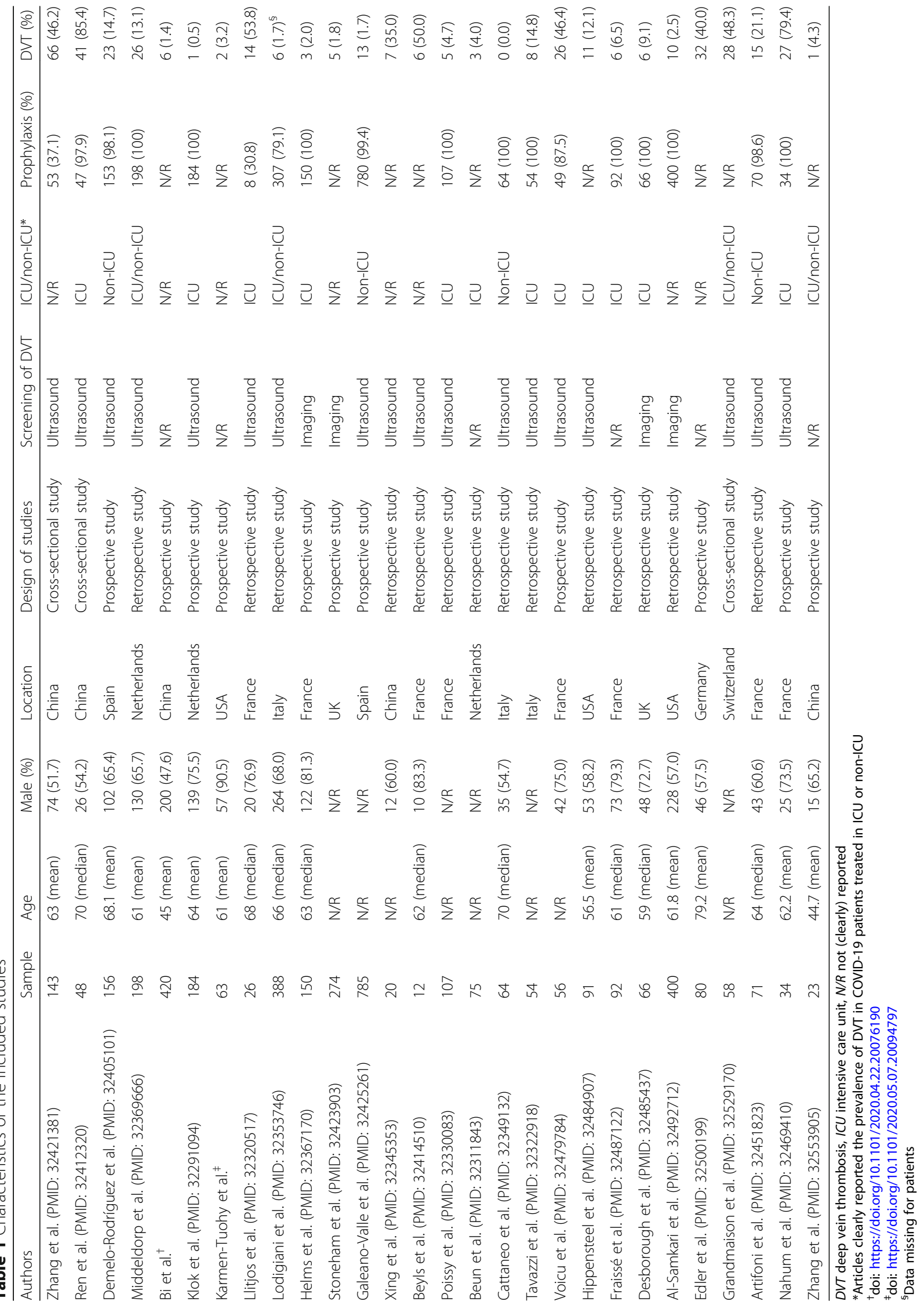




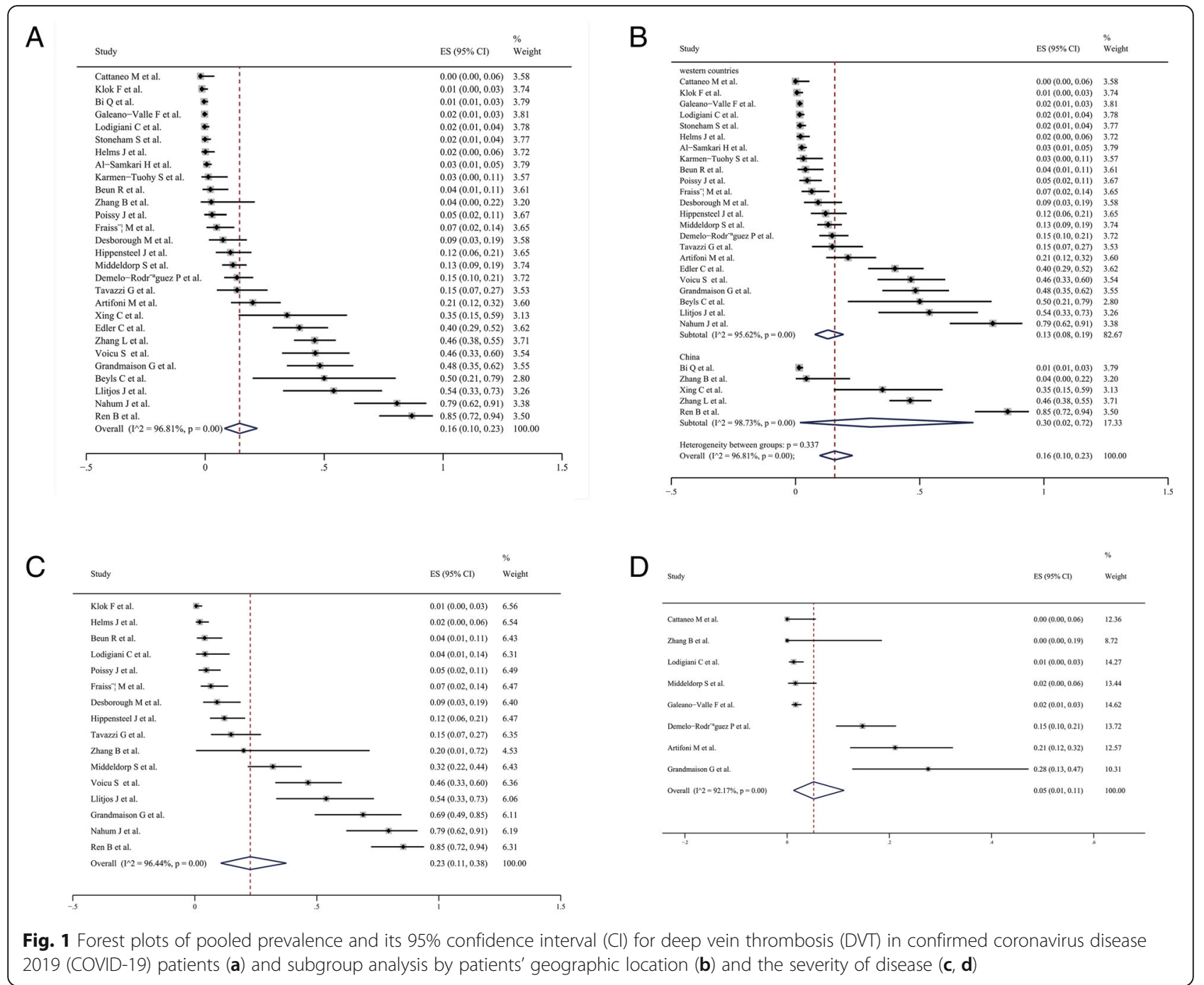

COVID-19 patients treated in ICU was 23\% (95\% CI $\left.11-38 \%, P<0.01, I^{2}=96.44 \%, Q=421.29, P<0.01\right)$, which was significantly higher than in COVID-19 patients treated in non-ICU $(5 \%, 95 \%$ CI $1-11 \%, P<$ 0.01, $I^{2}=92.17 \%, Q=89.42, P<0.01$ ) (Fig. 1c, d). We found significant publication bias by Egger's test $(P<0.001)$ and Begg's test $(P<0.001)$. The subgroup analysis showed that none of these factors could explain the significant heterogeneity. However, the meta-regression analysis of multiple covariates indicated that the geographic location of patients could partially explain heterogeneity $(P=0.036)$.

In conclusion, more attention should be paid to the prevention and clinical management of DVT, especially for COVID-19 patients in ICU, and timely assessment of DVT is essential. However, there was considerable heterogeneity in our meta-analysis. In addition, there was significant publication bias in our meta-analysis, although we searched four databases as many and as carefully as possible. Finally, we included non-survival patients who were seriously ill and may exaggerate the prevalence of DVT in COVID-19 patients.

\section{Acknowledgements}

Not applicable.

\section{Authors' contributions}

Ying Wang, Li Shi, and Yadong Wang designed the study, performed the analyses, and wrote the manuscript; Ying Wang, Li Shi, Haiyan Yang, and Guangcai Duan performed the statistics; and all authors critically reviewed and approved the manuscript.

\section{Funding}

This work was supported by the National Natural Science Foundation of China (no. 81973105). The funder has no role in the preparation of manuscript and decision to submission. 


\section{Availability of data and materials}

All data generated or analyzed during this study are included in this article.

Ethics approval and consent to participate

Not applicable.

\section{Consent for publication}

Not applicable.

\section{Competing interests}

The authors declare that they have no conflict of interests.

Received: 30 June 2020 Accepted: 15 July 2020

Published online: 28 July 2020

\section{References}

1. Ren B, Yan F, Deng Z, Zhang S, Xiao L, Wu M, Cai L. Extremely high incidence of lower extremity deep venous thrombosis in 48 patients with severe COVID-19 in Wuhan. Circulation. 2020. https://doi.org/10.1161/ circulationaha.120.047407.

2. Zhang L, Feng $X$, Zhang D, Jiang $C$, Mei H, Wang J, Zhang $C$, Li H, Xia X, Kong $S$, et al. Deep vein thrombosis in hospitalized patients with coronavirus disease 2019 (COVID-19) in Wuhan, China: prevalence, risk factors, and outcome. Circulation. 2020. https://doi.org/10.1161/ circulationaha.120.046702.

3. Klok FA, Kruip M, van der Meer NJM, Arbous MS, Gommers D, Kant KM, Kaptein FHJ, van Paassen J, Stals MAM, Huisman MV, et al. Incidence of thrombotic complications in critically ill ICU patients with COVID-19. Thromb Res. 2020. https://doi.org/10.1016/j.thromres.2020.04.013.

4. Middeldorp S, Coppens M, van Haaps TF, Foppen M, Vlaar AP, Müller MCA, Bouman CCS, Beenen LFM, Kootte RS, Heijmans J, et al. Incidence of venous thromboembolism in hospitalized patients with COVID-19. J Thrombosis Haemostasis. 2020. https://doi.org/10.1111/jth.14888.

5. Hargreaves S, Rustage K, Nellums LB, McAlpine A, Pocock N, Devakumar D, Aldridge RW, Abubakar I, Kristensen KL, Himmels JW, et al. Occupational health outcomes among international migrant workers: a systematic review and meta-analysis. Lancet Glob Health. 2019;7:e872-82. https://doi.org/10. 1016/S2214-109X(19)30204-9.

6. Newcombe RG. Two-sided confidence intervals for the single proportion: comparison of seven methods. Stat Med. 1998;17:857-72. https://doi.org/10. 1002/(sici)1097-0258(19980430)17:8<857::aid-sim777>3.0.co;2-e.

\section{Publisher's Note}

Springer Nature remains neutral with regard to jurisdictional claims in published maps and institutional affiliations.

Ready to submit your research? Choose BMC and benefit from:

- fast, convenient online submission

- thorough peer review by experienced researchers in your field

- rapid publication on acceptance

- support for research data, including large and complex data types

- gold Open Access which fosters wider collaboration and increased citations

- maximum visibility for your research: over $100 \mathrm{M}$ website views per year

At $\mathrm{BMC}$, research is always in progress.

Learn more biomedcentral.com/submissions 